Englishmen. The latest model of the Coolidge tube acts efficiently as its own rectifier, and the hightension outfit is correspondingly simplified.

In simple justice one must add that the scientific energies of this country have been far more distracted and dislocated by the war than have those of America. But the Department of Scientific and Industrial Research ought to have no hesitation in adding to the list of investigations it has tackled during and since the war.

To return to the question of future developments of the X-ray scrutiny of metals. The question of the light alloys is relatively simple, but for the heavier metals we need photographic plates and fluorescent screens of much higher efficiency. In addition, we need a method of generating $X$-rays in far greater abundance and of far greater hardness (i.e. shorter wave-length) than we have at present. In this connection every investigator and user ought to develop the habit of precise measurement of both current through the tube and, more important, the potential difference across the terminals. The voltage is commonly left to be inferred as well as may be from the alternative spark-gap between electrodes the size and shape of which are rarely mentioned. Or, more frequently, the hardness of the rays is given in some arbitrary unit difficult to define or reproduce. But radiology generally rejoices in a wealth of indefinite units and measuring instruments, mostly introduced bv workers who had enthusiasm but little physics. The subject of practical radiology has, unfortunately, been severely ignored by the physicist and the electrical engineer. Their assistance in this matter is earnestly needed both by the medical man and by the workers in this new field of the application of $\mathrm{X}$-rays to the examination of materials. The Röntgen Society has on its roll of members most of the younger X-ray physicists in the country, and we suggest that it should take early steps to co-ordinate the unrivalled experience and equipment of its physical and medical members for the ultimate benefit of British industry.

G. W. C. KAYE.

\section{RADIO-TELEGRAPHIC INVESTIGATIONS IN CONNECTION WITH THE SOLAR ECLIPSE OF MAY 29, 1919.}

I $T$ will be remembered that in a letter to Nature of February I3 last Sir Oliver Lodge, chairman of the British Association Committee for Radiotelegraphic Investigation, explained that his committee did not contemplate taking a very active part in organising wireless observations during the forthcoming solar eclipse, and hoped that parties travelling to the eclipse zone for the observation of astronomical, meteorological, and magnetic phenomena might be able to make wireless telegraph observations also. Later it was found that the various parties charged with the other observations would be too fully occupied to give any attention at all to wireless telegraphy, and therefore the committee has arranged for the carrying out of the experiments to be described below.

The umbra intersects the earth's surface in an approximate circle of diameter of about $234 \mathrm{~km}$. (I26 sea-miles), and it moves at the slowest at a speed of about $0.57 \mathrm{~km}$. (0.31 sea-mile) per second. Between II.30 and 12 (Greenwich mean time) it travels across Bolivia and Brazil, and crosses the Atlantic close to the equator between $I_{2}$ and $\mathrm{I}_{4.20}$. It then crosses the African continent from the French Congo to Mozambique. During the eclipse various wireless telegraph stations will emit signals consisting of letters of the alphabet changed according to a definite plan at the end of each minute; the programme of letters is so arranged that no two come together in the same NO. 2584 , VOL. IO3] order more than once. They will be accurately timed at selected receiving stations. By this arrangement the transmitting stations are relieved of the responsibility of timing the signals accurately, and the receiving operators have nothing to do but to write down each letter as they receive it and the number denoting its strength on the scale (o to 9) familiar to all wireless telegraphists. On the day before the eclipse the stations will send practice signals for a short time near noon (G.M.T.).

The British Admiralty stations at Ascension and the Azores will send continuously during the transit of the umbra across the Atlantic Ocean. Observing stations north of the equator will, for the most part, be asked to listen to Ascension for at least an hour round about the time when the umbra passes between themselves and Ascension. Similarly, observers south of the equator will be asked for the most part to listen to the Azores. Certain selected stations north of the equator will be asked to listen to the Azores so as to afford check observations upon the variations that may be observed in signals passing across the central line of the eclipse, and similarly selected stations south of the central line will be asked to listen to Ascension. The great American station at Annapolis may also transmit a programme during a portion of the period of the eclipse, and it is hoped that arrangements may be made for special experiments between a few pairs of stations, such as Darien and the Falkland Islands, and an Egyptian station and a South African station.

The main portion of the experiment hinges upon Ascension. The umbral cone passes from west to east, and may be expected to affect in succession the strength in which signals are received at such stations as Demerara, Jamaica, the stations on the coast of the United States and Canada, and stations in Ireland, England, France, Italy, the Mediterranean, and Egypt.

It is by the kindness of the American Government and of our own Admiralty that the stations at Darien and Annapolis, and at Ascension and in the Azores, are being used for the sending of the experimental waves. The Admiralty has, besides, provided many of the receiving stations both on land and sea, and other receiving stations are being put to work by the American, French, and Italian Governments, by our own Army and Air Force and also by the Marconi Co. in several parts of the globe.

The observers' results will be collated with the view of finding if the passage of the shadow cone between a sending and a receiving station causes any regular change in the strength of signals. According to some writers, the propagation of waves over long distances is greatly affected by the ionisation of the upper atmosphere. During a solar eclipse the cone of densest shadow removes all sunlight from the atmosphere within it, which may stop the ionising actions of sunlight and allow the recombination of separated ions to take place. This process starts in the penumbra, but it is accomplished fully, or to its fullest extent, only in the umbra. Thus at any particular fixed place in the air the penumbra, it is thought, first starts a gentle recombination of ions, and as the eclipse at that place progresses and darkness increases, recombination of ions takes place more and more quickly until the time of complete totality. Afterwards the onward passage of the umbral cone allows sunlight to begin again its ionising action. Something of this kind is, at any rate, supposed to be taking place at sunset and sunrise every day, and to be the main cause of the enormous variations experienced in signal strengths at those times.

It is sometimes supposed that the electric waves carrying signals take a curved trajectory in the atmo- 
sphere from one point to another. In this case signals passing between two stations at a short distance apart will traverse lower levels of the atmosphere than those passing between stations separated by a great distance. The eclipse probably affects the ionisation of the upper and lower layers of the atmosphere differently, and therefore we may expect to get different effects on long- and short-range signals. Moreover, it has been shown to be probable that long waves are more affected than short waves by changes of the ionisation of the air through which they travel. The elucidation of this point is one of the aims of the observations.

Anyone desirous of obtaining further information should communicate with Dr. W. Eccles, honorary secretary of the committee, City and Guilds Technical College, Leonard Street, London, E.C.2.

\section{THE BUREAU OF STANDARDS AND THE $W A R$.}

T HE most obviously noteworthy feature of Dr. Stratton's report on the work of the U.S. Bureau of Standards for the year ended June 30, I9I8, is the very extensive field of investigation covered. A large part of the work was necessarily related to the war; the expenditure increased from about $140,000 l$. in I9I6-I7 to more than $600,000 l$. in $1917-18$, of which 220,00ol. appears under the head of "National Security and Defence," and is made up mainly of sums expended on new buildings and laboratories, additional to the growth of ordinary expenditure due to war conditions. The value of the tests made, chiefly for the Government, is given as $20,000 \mathrm{l}$; ; and the number of persons employed as 1405 , of whom 839 were engaged in research and investigations specially authorised by Congress. The figures are useful as an indication of the expansion which has taken place.

The report opens with a brief account of the functions and organisation of the Bureau, which, if space permitted, it would be interesting to review in detail. It affords a valuable study in these days of reconstruction. The functions of the Bureau are stated to be the "development, construction, custody, and maintenance of reference and working standards, and their intercomparison, improvement, and application in science, engineering, industry, and commerce"; while the standards are classified under the five headings: standards of measurement, standard constants, standards of quality (of materials), standards of performance (of machines and devices), and standards of practice. The relations of the work of the Bureau to the public and to the Government service are examined in a manner which brings out prominently the important rofle the institution plays in connection with the national life and industry.

The remainder of the report, some 180 pages, deals, for the most part in short paragraphs, with the innumerable items of research and test work which have received attention in the various scientific and technical divisions. These departmental reports contain little more, in many instances, than a concise statement of matters investigated; in turning over the pages, among the many points of interest, a few only can be selected for comment. A new equipment has been provided for measuring expansion up to temperatures above $900^{\circ} \mathrm{C}$. The examination of minescales, used for weighing coal mined, led to the detection and removal of serious errors due to faulty weights, improper installation, and neglect in maintenance. The testing of gauges for the Ordnance Department was undertaken by the Bureau, as in this country by the National Physical Laboratory, though on a much smaller scale than here. Branches were No. 2584 , VOL. IO3] established at New York and elsewhere, and the manufacture of gauges was commenced.

In the electrical department ignition in petrol engines was studied, and improved porcelains for sparking plugs, developed by the ceramic laboratory, were put into production. A special method was devised for determining the velocity of projectiles. The method of "magnetic analysis" as a criterion of the quality of steel has been further investigated and applied in practice. The photometric work included tests of field searchlights and the investigation of gasfilled standards of spherical candle-power. For wireless work a new building was nearly completed. Sound-ranging was among the problems taken up by one of the electrical sections. An account is given of the relation of the Bureau to municipalities and public service commissions in securing safety and standardisation in connection with electricity and gas supply; some particulars are included of the national electrical safety code. The subject of electrolysis of underground pipes, cables, and other metal structures from stray earth-currents is prominently mentioned, and may need to be taken up actively in this country.

In the work of the heat department may be noted the determination of refrigeration constants, including the thermal constants of ammonia. The fire-resisting properties of structural materials, reinforced concrete, etc. under load were examined. An apparatus was completed for strength tests of metals at temperatures up to $800^{\circ} \mathrm{C}$. The work on aeroplane power plant included the construction of an altitude laboratory for engine tests under reduced pressure and at various temperatures, and a number of tests on engines have been carried out. The construction of radiators has also been the subject of research.

The researches in the optics department have included much spectroscopic work, dealing especially with the red and infra-red regions of the spectrum, landscape photography with red-sensitive plates, colour-filters, etc. The great value of red-sensitive plates in penetrating haze has been demonstrated, and another important characteristic of these plates is said to be their power to detect camouflage designed to defeat the eye. Quantitative, as well as qualitative, methods of spectroscopic analysis have been employed. Polarimetry has received much attention, especially in connection with the estimation of sugar, and interesting results have been obtained with regard to the natural rotation of quartz at high temperatures ; an abrupt change was found to occur at about $574^{\circ} \mathrm{C}$. In connection with the polarimetric work intense monochromatic light sources were necessary, and, after experiment with cadmium amalgam lamps, a lamp using a new allov has been produced. A novel method for the production of artificial daylight makes use of the rotatory dispersion of quartz.

A considerable amount of attention in the optics and chemistry departments has been given to the production of optical glass. The Bureau is said to be shipping glass in quantity for the manufacture of optical instruments. Some seven or eight varieties of the most used glasses are being produced, including a dense barium crown. For this work a new glass laboratory was erected in 1917. Much investigation has necessarily been devoted in this connection to the production of pots for melting.

The work of the chemistry section has included the study of electroplating and electrotyping; the improvement of the electrolytic method of estimation of carbon in steel so that an accurate determination can now be made in $4 \frac{1}{2}$ minutes; the testing of balloon fabrics and the investigation of balloon gases, together with chemical work on oils, rubber, paper, textiles, ink, glue, cement, bitumen, and other materials. It 